\title{
Gendered patterns in the construction of physics identity from motivational factors
}

\author{
Z. Yasemin Kalender® ${ }^{1}$ Emily Marshman, ${ }^{2}$ Christian D. Schunn, ${ }^{3}$ \\ Timothy J. Nokes-Malach, ${ }^{3}$ and Chandralekha Singh ${ }^{1}$ \\ ${ }^{1}$ Department of Physics and Astronomy, University of Pittsburgh, Pittsburgh, Pennsylvania 15260, USA \\ ${ }^{2}$ Department of Physics, Community College of Allegheny County, Pittsburgh, Pennsylvania 15212, USA \\ ${ }^{3}$ Learning Research and Development Center, University of Pittsburgh, Pittsburgh, Pennsylvania 15260, USA
}

(Received 28 March 2019; published 27 August 2019)

\begin{abstract}
Students' intentions to persevere and their career choices in science, technology, engineering, and math fields can be impacted by their physics identities. Women are severely underrepresented at all levels in physics and engineering. Physics in particular has stereotypes about being a discipline for brilliant men. Therefore, it is particularly difficult for women who do not fit the description of a stereotypical physicist to develop a physics identity. Thus, understanding the factors underlying physics identity in introductory physics classrooms is important for creating an equitable and inclusive physics learning environment and has the potential to at least partly explain the current underrepresentation of women in physics-related majors and careers. In this study, we examined physics identity and several other motivational constructs of male and female students by administering a survey in introductory calculus-based physics courses at a large research university. We found gender differences in how students identify as a physics person and how their perceived recognition from others, such as their teaching assistants or instructors, peers, or family members relates to their physics identities. We tested separate models by gender that examined how different motivational constructs relate to students' physics identities. We found that the perception of being recognized by influential others such as the course instructor or teaching assistants was differentially related to female and male students' physics self-efficacy and sense of belonging in the physics classroom. These findings call for improving the physics learning environments to make them equitable so that all students have a high sense of belonging and self-efficacy and opportunity to develop a strong physics identity.
\end{abstract}

DOI: 10.1103/PhysRevPhysEducRes.15.020119

\section{INTRODUCTION AND GOAL}

Among science, technology, engineering, and math (STEM) degrees awarded in the United States, there is a pervasive issue of low diversity that signals an alarming lack of participation, retention, and advancement of women and underrepresented racial and ethnic minorities [1-4]. Recent work has identified some of the factors and mechanisms underlying the lack of diversity in many STEM disciplines, see a review in Ref. [5], but much remains to be investigated. These ongoing efforts have shown some progress, such that the numbers of female students in some STEM majors (e.g., biology) have dramatically increased in the last few decades [1]. However, there are still other STEM domains, such as computer science, math, and physics, in which women are severely underrepresented [1].

In the physics community, researchers have started to focus on why certain groups of students, such as women,

Published by the American Physical Society under the terms of the Creative Commons Attribution 4.0 International license. Further distribution of this work must maintain attribution to the author(s) and the published article's title, journal citation, and DOI. are not represented equitably and do not pursue physics or physics-intensive fields as a career in proportions that are vital for enhancing the field [6-17]. This research has included an examination of motivational characteristics, such as students' epistemological beliefs about and attitudes toward physics learning [18-35]. Many motivational factors have been shown to affect students' engagement, persistence, and achievement in STEM learning [36-41]. For historically underrepresented student groups such as women, these motivational characteristics might be compromised due to negative societal stereotypes and biases, lack of encouragement in informal and formal settings from a very early age, and inadequate prior preparation due to accumulated disadvantages over the lifetime resulting from the biases and stereotypes [42-51]. Hence, investigating the differences in motivational factors within different student demographics is critical to understanding and addressing issues related to diversity, equity, and inclusion in the physics community.

Here, we describe a study of students' motivational characteristics in introductory physics courses taught at a large, public research university. In particular, we examined the physical science, math, and engineering students' "physics identity" in the first year of college, a critical 
time during which the majority of them experience collegelevel physics for the first time. These calculus-based physics courses are particularly important to study because women are consistently numerical minorities (female students roughly make up $30 \%$ of the classes), which can, in part, contribute to the differences in the development of female and male students' physics identities (over and above all of the accumulated societal stereotypes that individuals are exposed to growing up) and can impact their career choices. Therefore, our primary research interest is to understand how male and female students construct their physics identities based on other motivational factors that are closely relevant to students' learning experiences. In particular, we focus on the gendered patterns in students' physics identities and the ways in which motivational factors influence the development of students' physics identity as STEM majors in calculus-based physics courses.

Our goal is to investigate variation by gender in the connections between several key motivational factors including physics self-efficacy, interest, and value, as well as having a sense of belonging in the physics classroom. By using a factor analysis approach, we aim to understand how these motivational factors relate to students' internal (perception about self) and external (perception of others' recognition) physics identities. Conducting the factor analysis separately by gender allows us to test the extent to which different motivational factors (self-efficacy, sense of belonging, interest, and value) are integrated into female and male students' internal and external physics identities.

\section{BACKGROUND}

\section{A. Student attitudes, beliefs, and identity related to physics}

In a learning environment, a variety of motivational beliefs and attitudes, such as students' goal orientations [52-54], expectations for success, and beliefs and attitudes in the classroom, have been linked to academic outcomes [18-25,36,40,51,54-60]. Students with positive motivational beliefs and attitudes exhibit better use of self-regulated learning strategies, participate more in class activities, and show higher-level cognitive processing of the course material [60]. Students' attitudes in a classroom may also impact their other educational achievement or behavior. For instance, higher interest in a subject can lead to having higher motivation to engage with related learning opportunities more often [61]. According to expectancy value theory (EVT), interest can be shaped by students' beliefs about their ability such as self-efficacy $[62,63]$ or their expectation of the outcome [63]. This relation can also act in the other direction in that self-efficacy can be influenced by students' interest [62] and can impact students' learning outcomes [60].

Identity in a particular STEM discipline has been positioned as a particularly central driver of students' participation, career intentions, and professional choices in many disciplines [64]. For example, having a strong science identity was associated with a higher likelihood of minority students choosing science-related occupations [65]. In physics, high school experiences were linked to physics identity formation, which were then linked with later career intentions [33]. Several other studies extended these findings to identities in other related STEM disciplines, such as mathematics and engineering [66,67]. In one of these studies, physics identity and math identity were found to be strong predictors of engineering choices [68].

However, forming a science topical identity, e.g., a physics identity, can be difficult for women and underrepresented racial and ethnic minorities because they must negotiate conflicts between a science identity and the demographic identities of being a woman or a person of color due to societal stereotypes and biases [69-72]. In particular, societal stereotypes and biases lead to female and male students being exposed to different prior experiences from elementary school through high school and college that can severely disadvantage female students. These differential gender-based prior learning experiences can include lack of encouragements from family, mentors, or advisors pertaining to these fields. Lack of opportunity to take engaging science courses prior to college can be responsible for gender differences in students' STEM interest and persistence that can relate to students' identities in math and science domains [68]. For instance, fewer girls take advance placement physics classes or tests in high school than boys [73], which can be an important opportunity to develop physics and science identity before students make career-related choices. We note that in prior research, in general, the challenges women face in developing physics identities due to societal biases and stereotypes have been examined through qualitative studies in middle and high school contexts [74], during the time that students pursue undergraduate physics degrees [75], and doctoral degrees in astrophysics [76].

Relatedly, negative societal stereotypes and generalizations about who can succeed in physics and other STEM disciplines $[42,77,78]$ can lower women's sense of belonging and undermine their experiences, so that they may not form the necessary STEM identities as often as men do. These preconceptions regarding students' competence mostly favor male students over female students [79]. In general, being a genius or exceptionally smart is attributed to boys [80], and starting from early ages, boys and girls are externally exposed to these fixed intelligence views, e.g., about physics, in our society and begin to internalize them [81]. One study found that women are underrepresented in fields, such as physics, that associate being "brilliant" with being successful [82]. Furthermore, norms of science curricula also promote the stereotypical view that science is for high achievers or naturally gifted students [74], and women believe that they must achieve at exceptionally high levels in math and science to compete with men and be 
successful in many STEM professions [45]. Likewise, due to implicit or explicit bias, instructors more often praise male students for correct answers, while they overlook female students' displays of correct knowledge [83]. Moreover, when instructors praise students' performance as a sign of their intelligence rather than their effort, students can adopt fixed mindset views (i.e., intelligence is a fixed trait and innate intelligence that only men have is necessary to become successful in physics) [58]. A recent study found that STEM faculty, who endorsed fixed mindset beliefs (i.e., they believed some students have innate talent and others do not), had larger achievement gaps and inspired fewer students to succeed in their classes [84]. Therefore, we believe that gender-based generalizations can have a substantial differential influence on the mechanism of identity formation in physics.

\section{B. Motivational factors that are the foundations of students' physics identity}

In Gee's foundational theoretical framework, identity is described as "the 'kind of person' one is seeking to be and enact in the here and now" [71]. Individuals can have multiple identities that are based upon personality, roles, interactions with others, and social group memberships, and these together define the individuals' core identities $[85,86]$. Under this broad definition, domain-specific (e.g., physics) identities form a subset. In particular, a domainspecific identity can be defined as a collection of distinctive characteristics shared by all members of a particular social group (e.g., examining students' STEM identities shared by the members of STEM community) [86]. Domain-specific identities can explain why individuals may decide whether or not to become involved in and progress within the particular domain. For instance, understanding students' science identity may act as a lens in explaining their academic and professional career choices $[33,69]$.

Another important distinction involves internal vs external identity. Internal identity pertains to an individual's own perception of how they identify themselves within the domain. External identity, on the other hand, focuses on perceptions of how other individuals interpret one's identity, whether it is based on one's actions in a given domain or stereotypes. Since there are many possible others that may have different perceptions, research has identified three critical groups of others: family, friends, instructor or teaching assistant (TA) [33]. Note that in both cases, it is the individual's perception (about oneself or others' perception of oneself), because the individual's perception is what drives personal choices. There is a basic drive to have a coherent identity in which internal and external identities agree, and thus each can influence the other [87]. However, at a given point in time, experiences may lead internal and external identities to be out of alignment with another (e.g., an instructor provides ambiguous comments or comments based on very limited interactions can impact a student's identity in a discipline).

Some studies have found sizable gender differences in students' physics identities (i.e., male students in a course, on average, having stronger physics identities), mirroring the representation gap in the physics community $[33,66]$. The open question pertains to why the difference occurs although the researchers have hypothesized the underlying role of stereotypes and biases. The shared working theory is that identity is built upon other motivational factors, and these other motivational factors are shaped by experiences in and out of class (e.g., interactions with peers, teaching assistants, or instructors in different circumstances and learning environments) $[33,66,67]$. Thus, the prior literature typically has three related assumptions: (i) that women experience stereotype messages, microaggressions, male-dominated classrooms, male-only role models in physics; (ii) these gendered experiences influence foundational motivational beliefs and attitudes towards physics; and (iii) gender differences in these foundational motivational beliefs and attitudes towards physics due to stereotypes and biases produce gender differences in physics identity. In the current study, we expand on the prior research and investigate the connection between gender and foundational motivational factors and how these connections relate to male and female students' physics identities in calculus-based introductory physics (see Fig. 1). Although not tested directly, we hypothesize that if gender differences in physics identity are found due to stereotypes and biases regarding physics and physics-related careers, fewer women will pursue such careers.

What are the foundational motivational factors that explain the physics identity across gender? The widely used expectancy value theory proposed by Eccles et al. integrates three of the foundational motivational factors: expectations for success, subjective task value, and intrinsic interest [63]. The first portion of the model—expectancyinvolves individuals' beliefs about how well they will do in a task in either the near or distant future and borrows from Bandura's concept of self-efficacy [88]. Self-efficacy, in particular, can thrust a student into a feedback loop which can impact students' self-efficacy and performance in a positive or negative way. As students complete short-term goals (e.g., complete a physics course requirement for a STEM major), they obtain certain feedback about their performance that further shapes their self-efficacy. Furthermore, prior research has routinely shown large gender differences in students' physics self-efficacy with male students having higher self-efficacy $[18,20-$ $22,30,32,34,35]$. Several models have proposed self-efficacy as a foundation of identity [89]. We note that stereotypes often undermine individuals' self-efficacy by increasing their anxiety (which can reduce the level of engagement and time on task) and can cause them to perform worse in test-taking situations than they actually 


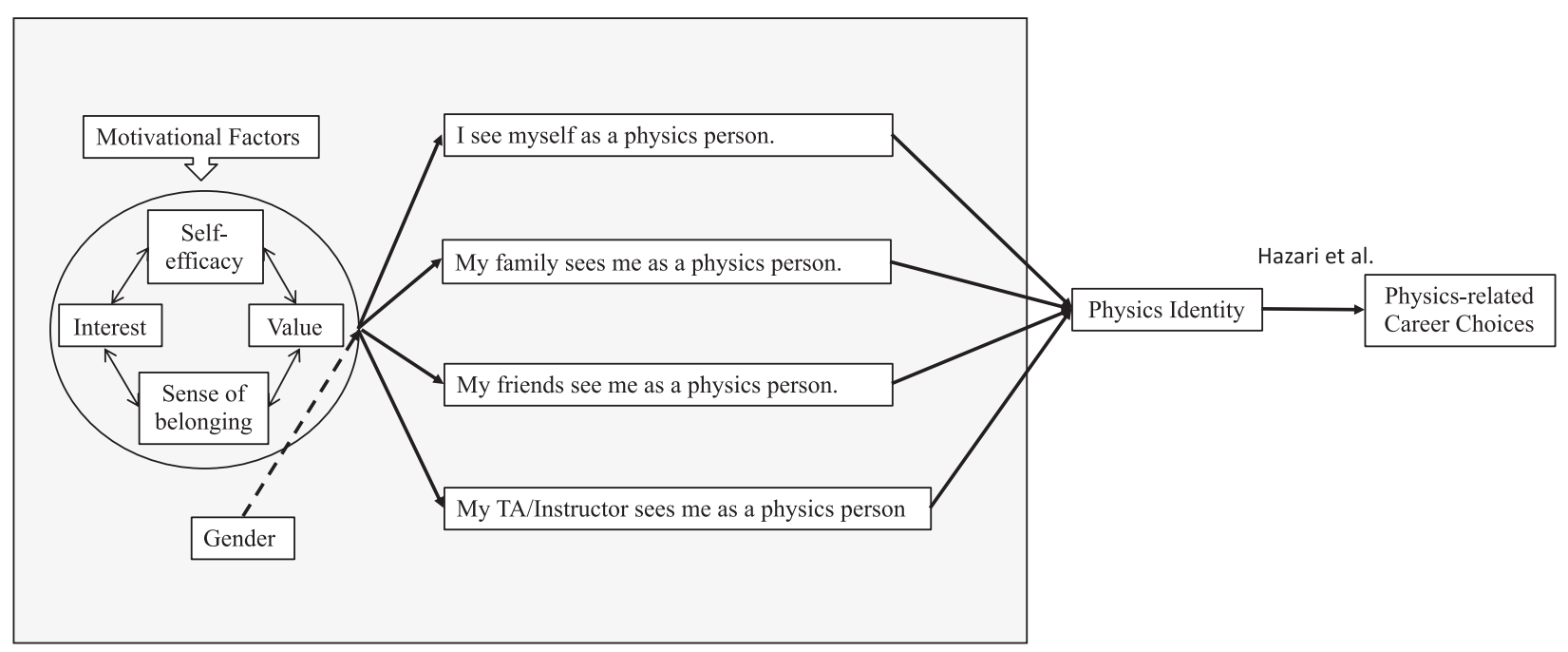

FIG. 1. Schematic representation of gendered relationships of four motivational factors to the components of physics identity (internal and external), which has been previously linked to career choices [33]. While "I see myself as a physics person" represents the "internal" aspect of physics identity, the other three Physics Identity items related to others' recognition (perception of my family, my friends, and my TA or instructor's views) represent students' "external" physics identity.

can due to the limitations on working memory (part of the working memory is robbed by the anxiety when solving problems) [90,91]. Research suggests that women who feel stereotyped have lower science-related aspirations [92]. Students might rely on such stereotypes (whether they are positive or negative). For instance, ambiguous situations can be one of the many situations in which stereotype threat can be activated. In the first semester of university, students are not familiar with college course sequences, and they need assurance for their performance as well as their choice of major [78]. In particular, for underrepresented students who experience stereotype threat, belonging uncertainties in a particular setting may become even more heightened in ambiguous situations $[92,93]$.

The second part of the EVT model-value-actually involves multiple components. The most commonly discussed value components are intrinsic value (enjoyment) and utility value (usefulness). When individuals perceive a task or domain as intrinsically valuable or extrinsically valuable to their goals, this can promote better engagement and motivation $[33,63,69,94]$. Intrinsic value in the original model is now often discussed as interest, which is defined by positive emotions accompanied by curiosity and engagement in the particular content [95-97]. Relatedly, Hidi and Renninger investigated several phases of how to form and increase interest in specific domains. Their model, in particular, highlights that interest cannot be maintained unless it is supported by the environment [96]. For instance, teachers need to encourage students by providing them useful feedback and providing mentoring and support that can bolster students' interest in the subject being taught. Several models have been proposed regarding both utility value and interest being foundational to the development of individual's identity in a domain
$[63,95]$, although other models propose closer connections mainly to interest $[39,95]$.

Sense of belonging is not part of EVT, but is another factor that has been proposed as important to the development of an individual's identity in a domain [98,99]. It pertains to making students feel that they belong within a particular community [99]. The feeling of belongingness is related to being valued, respected, and accepted in academic spaces [99]. Studies suggest that women in STEM fields might have lower levels of sense of belonging due to societal cues and masculine culture of STEM $[77,100]$. Furthermore, implicitly or explicitly biased attitudes of faculty (e.g., academic advisors, instructors, or graduate teaching assistants) can also make women feel that they do not belong in the community [78]. Therefore, developing a strong sense of belonging in science courses can be a significant factor in whether and when students start building their identity as a scientist.

\section{Theoretical model}

In this study, we test a model that physics identity is developed from four key motivational factors (see Fig. 1): self-efficacy, interest, value, and sense of belonging in a physics course. These factors are thought to affect both whether students view themselves as a physics person and whether they perceive that others recognize them as a physics person (these internal and external identities can interact with each other to form an individual's identity in a particular domain as discussed earlier). There are numerous studies that establish the role of physics identity in career intentions and choices in the STEM fields $[33,66,68,75,76]$, but there are very few studies that have attempted to explore the connection between motivational factors and identity 
formation [89]. Moreover, no prior studies have examined whether the connections between the motivational factors and identity is gender specific in calculus-based physics courses. These issues are important to investigate in order to create equitable and inclusive learning environments in physics, a domain with pervasive stereotypes and biases.

There are multiple ways in which identity in a discipline, e.g., physics, could be differentially related to motivational factors. For example, in one proposed model, identity could be a coherent and independent construct from the other motivational factors across both genders, but there may be differential strengths of association between identity and the motivational factors (e.g., a stronger connection between physics identity and self-efficacy in women compared to men). This theoretical model can be tested using factor analysis and regression. For example, operationally, a factor analysis would produce a separate factor for identity, and then regression analysis would find differential relationships between the foundational motivational factors and identity (e.g., significant interaction terms between gender and a motivational component in the multiple regression).

In a second proposed model, identity could be so closely aligned with one of the motivational factors that it does not produce a separate factor, but which factor identity aligns with varies by gender (e.g., identity aligns with interest in men but with self-efficacy or competency beliefs in women). If this model is correct, operationally, a factor analysis would not produce a separate factor for identity but generate loadings under one of the motivational constructs proposed in our model such as interest, self-efficacy, value, or sense of belonging. Relatedly, the factor analyses done separately by gender would produce different alignments for how physics identity items load under different constructs. For instance, the identity items can factor under sense of belonging for female students while they load under interest for male students. In terms of underlying mechanisms, the two options could be actually similar, and the second option is just a derivative case. In other words, we would find that identity items factor out under a particular construct for both gender groups or there might also be differences across gender in terms of the factor under which the identity components load.

In a third proposed model, the different components of identity (internal vs external) do not cohere with each other overall but do so only within each gender (as proposed in the second model). Although individuals seek to have coherent identities in which the way they perceive themselves is consistent with how others view them, in cases of pervasive stereotypes and biases, the underrepresented groups can perceive mismatches between how they think of themselves and how others think of them. In particular, internal identity might be closely connected to interest but external identity, in the case of women, might be closely connected to self-efficacy or sense of belonging due to the stereotype about "brilliance" and women's ability to excel in physics. The third model adds further dimension to our interpretation in which the identity components themselves show differences in how they factor out and there might also be an interaction effect when we investigate the connection with gender. For instance, men's internal and external identities can factor under one of the motivational constructs such as interest but there might be differences between the internal and external identities for women.

In this study, students who take the motivational survey are in a calculus-based introductory physics course which is required for many STEM majors (engineering students and physical science and mathematics majors) and all students must successfully complete the course with a $\mathrm{C}$ grade in order to continue in their STEM majors. Assessing students' physics identities in this introductory level physics can be valuable especially in understanding retention issues of underrepresented groups, e.g., women in STEM. Hazari et al. [33] showed that students' physics identities in high school predict their later physics-related career choices. Godwin et al. later used this identity framework with a general population of college students; they found that students' physics identity predicted their engineering choices [68]. In addition to the important role of students' physics and engineering identities on their STEM (physics and engineering) career choices, understanding the identity formation of students across gender (and how different motivational factors are related to it) can also shed light on the gender-based differential choices of STEM majors during their first year in college [37]. Since we focus upon calculus-based physics-a fundamental course in STEM curricula, taken by all engineering, physical science, and math majors-performance in this gateway course predicts students' success later in various academic program [101]. Therefore, examining the ways in which the physics identities of male and female first year students in this introductory level physics course are related to different motivational factors is particularly important and central to our research question. This is a critical issue to investigate to improve the physics learning environments particularly because of the gender stereotypes and biases associated with physics that disadvantage women from a very early stage. Our primary research question is, "How do different motivational factors relate to male and female students' internal and external physics identities in a first-year calculus-based introductory physics course?" In addressing this question, we aim to understand how the motivational survey data relate to each of the three possible models described earlier.

\section{METHODOLOGY}

\section{A. Development of motivational survey and instrument validity}

This study used previously validated surveys to measure students' physics identity, self-efficacy, interest, and sense 
of belonging for students enrolled in calculus-based physics courses. All of the motivational constructs were embedded in the context of physics (e.g., self-efficacy in physics). The survey instruments were part of a larger survey that included other motivational constructs (see Appendix B). The development and validation of these surveys is reported in prior work [18-22,59]. The surveys were based upon previous instruments [24,102-106] and validation of the revised instruments involved iterative use of exploratory factor analysis (EFA), confirmatory factor analysis (CFA), inter-item reliability to check consistency of the items, and one-on-one student interviews both with introductory undergraduate and graduate students $[18,59]$.

The Physics Identity survey evaluated the extent to which students see themselves as a physics person and their perception about whether others see them as a physics person [33]. The Interest in Physics survey measured students' enthusiasm in learning physical laws and their curiosity about cutting-edge research in physics [102]. The Value of Physics survey focused on students' views of whether learning physics will help them succeed in their major or later STEM career [102]. The Physics Self-efficacy survey measured students' confidence in their ability to understand and solve physics problems [102-105]. Finally, the Sense of Belonging survey measured whether students feel that they belong in the surveyed (introductory physics) classroom or not [106], and it focused on students' sense of being accepted and valued by their peers and instructors or TAs in the class [99].

The items in the survey were designed on a Likert scale of 1 (low endorsement) to 4 (high endorsement) (for sense of belonging, 1 to 5) [107]. The specific rating scales were purposely varied to provide a more valid overall measure of intensity by including frequency (e.g., never, once a month, once a week, every day) and intensity (NO!, no, yes, YES!; strongly disagree, disagree, agree, strongly agree). While having a lower score was an indication of negative endorsement (e.g., lower level of interest, self-efficacy, value, identity, and sense of belonging), higher scores corresponded to more positive beliefs (e.g., average selfefficacy score of 4 referred to the highest confidence level for a student). Some questions were reverse coded. For instance, one of the items in the sense of belonging part of the survey was "Sometimes I worry that I do not belong in this physics class." A student responding to this question as "mostly true" was given a score of 2 . We only included 2-3 such reverse-coded questions because too many reversecoded questions could create ambiguity for respondents.

Table I shows all the constructs and the observed scale reliabilities in this dataset (Cronbach's $\alpha$ ) for each motivational construct [108]. The Cronbach's $\alpha$ reliabilities were good $(>0.8)$ or excellent $(>0.9)$ [108]. We calculated mean scores for each motivational construct that showed roughly equal separation between levels on the Likert scales. For example, a student who answered "Yes!" to three of the self-efficacy questions and "no" to the other two selfefficacy questions would have an average self-efficacy score of $(4+4+4+2+2) / 5=3.2$.

\section{B. Participants}

The 559 participants completing the surveys were students enrolled in one of four different sections of introductory calculus-based physics, and each section was taught by a different instructor. This course is generally taken by engineering and physical science students in their first year of undergraduate studies.

Students' demographic information such as age, gender, ethnic or racial, and academic major information were provided by the university using an honest broker process that linked survey responses with students' demographics in a de-identified way. Based on this university data, the survey

TABLE I. For each motivational construct, number of items, sample items, Likert scale range, and observed Cronbach $\alpha$. The symbol $R$ at the end of an item corresponds to a reverse coded item.

\begin{tabular}{|c|c|c|c|c|}
\hline Measure & $\begin{array}{l}\text { No. of } \\
\text { items }\end{array}$ & Sample item & Likert scale & Cronbachs' $\alpha$ \\
\hline Physics identity [33] & 4 & $\begin{array}{l}\text { - I see myself as a physics person } \\
\text { - My friends see me as a physics person }\end{array}$ & $(1-4)$ & 0.90 \\
\hline Interest in physics [102] & 5 & $\begin{array}{l}\text { - I wonder about how physics works } \\
\text { - I am curious about the recent discoveries in physics }\end{array}$ & $(1-4)$ & 0.86 \\
\hline $\begin{array}{l}\text { Physics self-efficacy } \\
\qquad[102-105]\end{array}$ & 5 & $\begin{array}{l}\text { - If I encounter a setback in a physics exam, } \\
\text { I can overcome it } \\
\text { - I am able to help my classmates with physics } \\
\text { in the laboratory or in recitation. }\end{array}$ & $(1-4)$ & 0.83 \\
\hline Valuing physics [102] & 4 & $\begin{array}{l}\text { - Learning physics will help me succeed in my future career } \\
\text { - Learning physics will help me get a job that I want. }\end{array}$ & $(1-4)$ & 0.90 \\
\hline $\begin{array}{l}\text { Sense of belonging in physics } \\
\text { classrooms [106] }\end{array}$ & 5 & $\begin{array}{l}\text { - Sometimes I worry that I do not belong } \\
\text { in this physics class }(\mathrm{R}) \\
\text { - I feel like I can be myself in this class }\end{array}$ & $(1-5)$ & 0.84 \\
\hline
\end{tabular}


participants were $33 \%$ female and $67 \%$ male students; one student did not have a reported gender status and was excluded from further analysis. In terms of ethnic or racial distribution, students were $77 \%$ White, $11 \%$ Asian, 4\% Latinx or Hispanic, 3\% Black, 4\% Multiracial, and 1\% Other. Regarding academic majors, $61 \%$ of students were in the engineering track and 39\% of students were in physical science majors. Also, $90 \%$ of the students were in their first year with an average age of 19 .

\section{Procedures}

The motivational survey was administered in paper form during the last recitation of the semester by the graduate teaching assistants. The survey took approximately 5-10 $\mathrm{min}$ for respondents to complete. Course instructors were encouraged to give students extra credit to participate in the survey. The survey response rate was $73 \%$ of students enrolled in the course. We have used the current dataset in a previous study to examine the attitudes that mediate the relation between gender and students' views of the extent to which they see themselves as a physics person [59]. In this study, we used the same dataset to carry out an in-depth analysis of the factors that influence the formation of female and male students' views of the extent to which they see themselves as a physics person as well as their perception about the extent to which others view them as a physics person.

\section{Analysis}

MANOVA analysis of gender differences in physics identity.-We first analyzed the survey data to compare the mean scores by gender for two components of physics identity. Multivariate analysis of variance (MANOVA) was used to test for statistical significance differences between female and male students on each identity component. MANOVA is appropriate when multiple correlated dependent measures are being examined in parallel. Based upon prior research, we selected the first question for physics identity - "I see myself as a physics person"-as a separate physics person construct which pertains to internal identity as discussed in the background [59]. Then we obtained an average score for three other identity questions that form students' external identity by labeling it as perceived recognition by others (i.e., by family, friends, and TA or instructor), based on work by Hazari et al. [33]. We also examined each identity item in the perceived recognition construct separately since there might be variations in students' responses depending on who is recognizing them as a physics person. For instance, students' perception about being recognized by friends vs by a TA or instructor may vary.

Principle component analysis by gender.-To test for gender differences in the motivational factors underlying the physics identity, we performed a principal component analysis (PCA), which is essentially an exploratory factor analysis. PCA is a widely used method to extract underlying dimensions within large datasets of survey data. Such a factor analysis is used to investigate how survey items show similar patterns to form the theoretical constructs (e.g., self-efficacy) [109]. The main goal of the factor analysis is to identify groups of items that can explain the largest variance in coherent underlying constructs [109]. In order to extract the constructs from a given set of survey items, we used the PCA method which assumes that there is no unique variance in items (i.e., all the variance in the items equals the common variance in the latent variables or factors). The output of the PCA analysis provides several statistics regarding the total variance explained by the items, the component matrix, and factor loadings. The PCA algorithm calculates eigenvalues and eigenvectors for each component (construct), then multiplies eigenvector of each item with the principle component eigenvalue. This calculation is the factor loading for each item (see Table II) and it represents how well each item in the survey correlates with the specific component construct in the analysis. In particular, the square of the factor loading for an item to a factor is related to the percentage of variance explained.

Separate PCAs were conducted for male student and female student data in order to understand whether male and female students' group identity (both internal and external) behaves in similar or different ways with other motivational constructs, both at the overall identity level and also for the different components of identity separately (see Fig. 1). With this framework, we tested the extent to which there were four independent motivational factors (selfefficacy, sense of belonging, interest, and value) and the extent to which these motivational factors were integrated into students' internal and external physics identities.

We implemented PCA using a Promax rotation with Kaiser normalization given that we expected the factors to be correlated with one another. We initially used the standard criterion of eigenvalues $>1$ for determining the number of extracted factors (components). We also examined the scree plot to observe the relative change in modeled variance with growing number of generated factors. The scree plot leveled off with three factors (see Fig. 3 in Appendix A), and results with more than three factors did not produce more theoretically coherent factors nor different patterns of results for the core research questions than models with three factors. Therefore, we focus on the PCA analysis results with three output factors.

We then analyzed the component loadings for each survey item in terms of their connection to each of the three resulting factors. Higher loading values correspond to a closer affinity with the particular factor. Researchers usually suppress the factor loading below 0.3 or 0.4 since those contribute very little to variance in the factor (which is the square of the factor loading). Therefore, we discuss results for 0.4 and above as the primary result, and between 0.3 and 0.4 as the secondary result. 
TABLE II. Factor loadings from the principle component analysis results for female and male students. Loadings $>0.4$ are in bold. Loadings below 0.3 are suppressed.

\begin{tabular}{|c|c|c|c|c|c|c|}
\hline \multirow[b]{3}{*}{ Questions } & \multicolumn{6}{|c|}{ Components } \\
\hline & \multicolumn{3}{|c|}{ Female } & \multicolumn{3}{|c|}{ Male } \\
\hline & $\begin{array}{c}\text { Interest } \\
\text { or identity }\end{array}$ & $\begin{array}{l}\text { Self-efficacy } \\
\text { or belonging }\end{array}$ & Value & $\begin{array}{c}\text { Interest } \\
\text { or identity }\end{array}$ & $\begin{array}{l}\text { Self-efficacy } \\
\text { or belonging }\end{array}$ & Value \\
\hline 1. I wonder about how physics works & 0.85 & & & 0.79 & & \\
\hline 2. In general, I find physics & 0.81 & & & 0.70 & & \\
\hline 3. I want to know everything I can about physics & 0.91 & & & 0.69 & & \\
\hline 4. I am curious about recent physics discoveries & 0.95 & & & 0.69 & & \\
\hline $\begin{array}{l}\text { 5. I want to know about the current research } \\
\text { that physicists are doing }\end{array}$ & 0.91 & & & 0.65 & & \\
\hline $\begin{array}{l}\text { 6. I am able to help my classmates with physics } \\
\text { in the laboratory or in recitation }\end{array}$ & & 0.67 & & 0.36 & 0.50 & \\
\hline 7. I understand concepts I have studied in physics & & 0.74 & & 0.35 & 0.51 & \\
\hline 8. If I wanted to, I could be good at physics research & & 0.52 & & 0.38 & 0.40 & \\
\hline 9. If I study, I will do well on a physics test & & 0.75 & & & 0.65 & \\
\hline 10. If I encounter a setback in a physics exam, I can overcome it & & 0.63 & & & 0.68 & \\
\hline 11. Learning physics will help me in courses in my major. & & & 0.79 & & & 0.81 \\
\hline $\begin{array}{l}\text { 12. Learning physics will help me achieve admission } \\
\text { into graduate school and/or medical school. }\end{array}$ & & & 0.84 & & & 0.78 \\
\hline 13. Learning physics will help me get a job that I want. & & & 0.98 & & & 0.81 \\
\hline 14. Learning physics will help me succeed in my future career. & & & 0.88 & & & 0.84 \\
\hline 15. I see myself as a physics person. & 0.64 & & & 0.68 & & \\
\hline 16. My family sees me as a physics person. & 0.46 & & & $\mathbf{0 . 8 2}$ & & \\
\hline 17. My friends see me as a physics person. & 0.51 & 0.33 & & 0.82 & & \\
\hline 18. My physics instructor and/or TA sees me as a physics person. & & 0.68 & & 0.56 & 0.34 & \\
\hline 19. I feel like an outsider in this class. & & 0.69 & & & 0.71 & \\
\hline 20. I feel comfortable in this class. & & 0.74 & & & 0.74 & \\
\hline 21. I feel like I can be myself in this class. & & 0.67 & & & 0.59 & \\
\hline 22. Sometimes I worry that I do not belong in this physics class. & & 0.89 & & & 0.88 & \\
\hline $\begin{array}{l}\text { 23. When I get a poor grade on a physics assignment } \\
\text { or exam, I feel that maybe I don't belong in physics class }\end{array}$ & & 0.98 & & & 0.80 & \\
\hline
\end{tabular}

\section{RESULTS AND DISCUSSION}

\section{A. Gender differences in physics identity items}

Comparing female and male students' average physics identity scores for each item in the survey, we found a gender gap in students' perception of both being a physics person and being recognized by others as a physics person (see Fig. 2). MANOVA with Wilks' test revealed that there is a statistically significant gender difference for all physics identity items in the survey $[F(1,556)=11.95$, $p<0.001]$. In other words, female students reported significantly lower identity scores than male students.

We also calculated effect sizes (Cohen's $d$ values) [110] of the gender gap in each physics identity item to provide a standardized measure (see Fig. 2). Effect sizes range from 0.4 to $\sim 0.6$ suggesting moderate level effect size, which correspond to approximately 0.5 standard deviation difference between female and male students' physics identities [110]. The gender gap becomes especially important when we consider that the data were collected at the end of first-year students' first semester, which is often a critical transition point for many STEM majors in engineering and physical sciences in terms of deciding whether to continue within STEM overall and select particular majors. The gender differences in identity are similar in size to the ones in interest $(d=0.63)$, self-efficacy $(d=0.55)$, and belonging $(d=0.51)$, and larger than the ones in value $(d=0.26)$.

Mean scores across family or friends' recognition were very similar. However, the mean score's for TA or instructor's recognition were lower than means for the other physics identity items in the survey. Using a paired $t$ test to contrast responses to Q18 against the mean of Q15-17, the difference was statistically significant for both female $(t=2.63, p<0.01)$ and male $(t=8.37, p<0.001)$ students. This analysis gives a clear demonstration that students' views regarding how others see them as a physics person might vary depending on the level of recognizer's role in students' learning (e.g., whether the person is a family member or TA or instructor), which can further impact how students see themselves as a physics person (as a result of receiving or not receiving this recognition). 


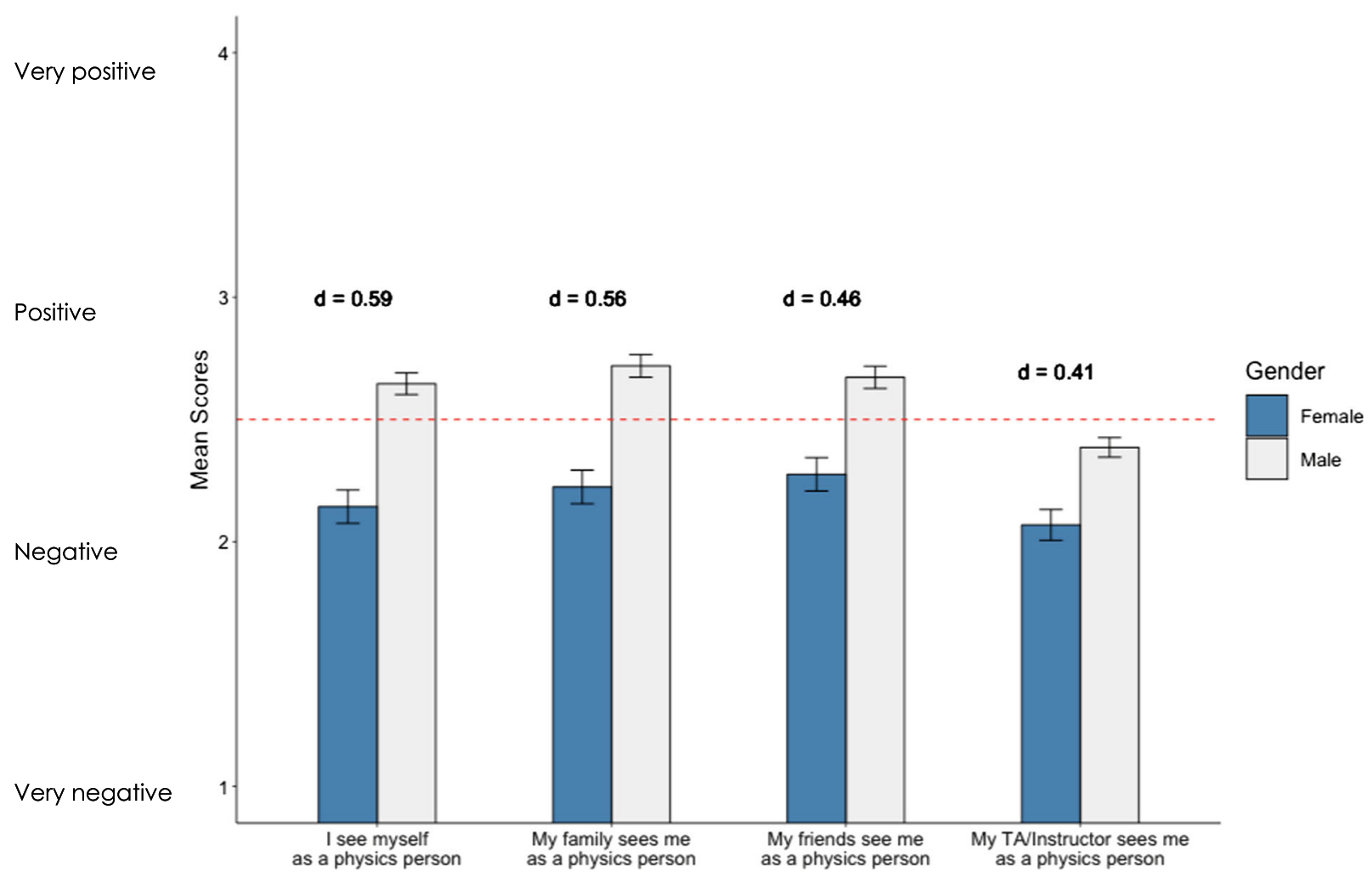

FIG. 2. Mean scores (with standard error bars) for each physics identity item for female and male students. All of the gender differences are statistically significant at the level of $p<0.001$. " $d$ " denotes Cohen's $d$ for the gender contrast. Red dotted line indicated the score of 2.5 , which corresponds to neural response for identity.

\section{B. Principle component analysis by gender}

The separate PCAs by gender resulted in several very important and intriguing findings (see the rotated factor matrix by gender in Table II). A commonly accepted but somewhat conservative analysis approach is to show and interpret only the factor loadings of 0.4 and above, which we call the primary results and show with boldface font in Table II. However, since the community also often interprets the values between 0.3 and 0.4 , we include those loadings in our analysis as secondary results. Items in this range may reflect items that are cross loaded across two dimensions or not as consistently interpreted. Viewing such items may reveal patterns in items just below a more conservative threshold.

For the primary results (factor loadings 0.4 and above), the estimated factor loadings or weights are similar for both gender groups in a number of ways. First, the items associated with "interest" and "value" dimensions consistently factored out as two separate constructs from one another for both men and women. Although more intrinsic and extrinsic motivational drivers are conceptually distinct within expectancy value theory, the two are often so highly correlated that it is hard to separate them within factor analysis [63]. It appears that within this population of engineering and physical science majors, interest in and value of physics are strongly independent components (each one has an average item factor weighting values greater than 0.7). Thus, the first component or factor in Table II is labeled as "interest" and the third component or factor is labeled as "value."

Second, the component related to self-efficacy, the third component of expectancy value theory, is a separate factor. Focusing on factor loadings above 0.4, the self-efficacy items consistently load on their own factor separate from interest and value, as predicted by expectancy value theory. The factor weights are somewhat lower, especially for items that are also loaded with weights between 0.3 and 0.4 on the interest scale.

Third, despite our initial hypothesis of having four separate motivational constructs (interest, value, selfefficacy, belonging) that might be separate or integrated with identity, the PCA analysis reveals that for both genders, sense of belonging and identity were not separate from the EVT constructs. Instead, sense of belonging was closely tied to self-efficacy, which was therefore labeled as "self-efficacy or belonging" component or factor. Both internal and external identity were closely tied (with one gendered exception) to interest dimension, which is therefore labeled "interest/identity."

There was one main and important difference between male and female students in the primary results: Q18 - "My TA or instructor see me as a physics person" is one of the external identities loaded similarly with the other Identity 
items (i.e., with Interest) for male students (with factor loading 0.56), however, it strongly factored with "selfefficacy or belonging" for female students (with factor loading 0.68). In other words, female students' perception of being recognized as a "physics person" by their TA or instructor is intimately related to their sense of belonging and self-efficacy in a physics classroom. By contrast, for male students, TA or instructor recognition was closely aligned with their internal interest in physics.

Next, we discuss the secondary results (weaker effect than the primary results) given in Table II, which includes factor loading values between 0.3 and 0.4. For male students, Q18 pertaining to perceived recognition of their TA or instructor shows a smaller connection to self-efficacy or belonging (0.34) unlike female students who have a higher factor loading for this item as discussed in the primary results. In particular, students' perception of getting recognition from their course instructor or teaching assistant appears to be generally important aspect for building positive self-efficacy and sense of belonging for all students, but this aspect of external identity is particularly strong for female students. Similarly, Q17 (My friends see me as a physics person) is another external identity item that also shows a gender difference in the secondary results. Q17 factors out under the "interest" component for male students with a high loading (0.82). For female students, the same item also shows a main contribution to the "interest" component (0.51), but there is an additional loading (0.33) under the self-efficacy or belonging component only for female students. In other words, female students' self-efficacy or belonging is positively related to recognition by friends as a physics person but not for male students, which again shows a distinction between female and male students' external identity formation. These results (for both Q17 and Q18) highlight that the extent to which students' physics identity integrates with other motivational factors may vary across gender particularly when they are externally driven identities.

Finally, Q1-Q5 measure students' interest and curiosity with discoveries in physics or current research in physics, and show a higher loading on the "interest" factor for female students compared to male students. We also note that the value component did not connect with any aspect of student's physics identity, even within the 0.3 to 0.4 factor loading range, for either gender. This suggests that motivational factors such as identity are more internal constructs, whereas utility value that one may derive from physics as measured by the validated survey is an external construct.

\section{SUMMARY AND GENERAL DISCUSSION}

This study investigated male and female students' physics identities — both internal and external—during an important transition point in the educational pathways for physical sciences and engineering: midway during a two-semester introductory-level calculus-based physics courses. Prior research has revealed the importance of physics identity on students' career intentions and choices in STEM, and therefore understanding why and how students' physics identity formation may differ across gender is critical to enhancing women's experiences and participation in physical science and engineering fields. Our novel results indicate a moderate level of gender differences in students' internal and external physics identities, in both their internal coherence and their relations to other motivational factors that have been previously linked to identity formation [89]. Moreover, while some of the motivational constructs shown in Fig. 1 such as self-efficacy, interest, and sense of belonging exhibited some gendered patterns in terms of how they factor out and relate to students' identities in physics, value as the other construct in the framework showed similar patterns across both genders (and was not related to external or internal components of physics identity).

In the research discussed here, we found that the components of expectancy value theory (interest, self-efficacy, utility value) were independent of one another but sense of belonging in physics was so strongly aligned with physics self-efficacy that it did not factor separately for either gender. A similar result was found for physics identity ("I see myself as a physics person") in that it was very strongly aligned with interest and they did not factor out separately for either gender. This result is consistent with the second proposed model in which physics identity was not found as a separate construct but closely related to other motivational constructs such as interest. Researchers rarely examine the factor structure of multiple motivational factors together. Our findings show that it is important to do so. In particular, this analysis sheds light on how different components of external and internal physics identity are related to other motivational factors (e.g., self-efficacy, interest, sense of belonging, and value) for men and women who were at the end of their first required calculus-based introductory physics course.

Another interesting finding of the factor analysis is the relation between the constructs of sense of belonging and self-efficacy in that they were found to load on the same factor instead of two distinct factors. In the literature, while students' physics self-efficacy across gender has been examined in numerous research studies [18,30,32,34,35], little regard has been given to examining students' sense of belonging in physics classes. Our finding suggests that students' sense of belonging at least in calculus-based introductory physics is strongly connected to their physics self-efficacy (in the exploratory factor analysis, the sense of belonging items, and self-efficacy items on the survey always factored under the same factor regardless of the number of factors considered). This is a very important finding because there are often large gender differences in self-efficacy according to prior studies. While the causal direction is ambiguous with the current data (e.g., self-efficacy causes sense of belonging or sense of belonging causes selfefficacy), prior research supports both directions $[99,111]$. Therefore, creating learning environments in which all 
students have a sense of belonging and feel comfortable to discuss their opinions and, in return, feel valued by peers and the instructor or TA is likely to be critical for increasing all students' self-efficacy in physics, particularly those who are underrepresented such as women.

Equally importantly, while there were general similarities across gender in how identity related to other motivational factors, especially in the internal identity item, in exploratory factor analysis there were some differences in students' external identities. In particular, factor analysis by gender gave consistent results with the second model in that female and male students' factor loadings for the external identity items that measure student's perception of how others see them as a physics person showed differences in terms of the alignment with the three main factors given in Table II. Q18: "My TA or instructor sees me as a physics person" factored with identity or interest for male students but with selfefficacy or belonging for female students. The primary results for Q17: "My friends see me as a physics person" showed a similar pattern. Furthermore, the results are also consistent with our model 3 in which we proposed that there might be some differences in how students see themselves as a physics person (internal identity) and how they think others see them as a physics person (external identity). This mismatch between the internal and external identity was more salient among female students as discussed above. In other words, for female students, internal identity was aligned with the interest or identity component (which is a similar pattern with male students) while the external identity such as peers or TA or instructor's recognition showed moderate or strong correlation under the self-efficacy or belonging component, respectively. Again, female students in calculus-based introductory physics course might interpret how others see them through a self-efficacy belief due to (implicit or explicit) messages of exclusion they have received related to societal stereotypes and biases.

Given that achievements and experiences in gateway courses, such as physics, are an important part of how students' STEM identities evolve [37], supporting female students' physics identity formation and bolstering their positive attitudes towards physics by creating equitable and inclusive learning environments may help sustain women's participation and advancement in STEM disciplines. In the next section, we discuss the possible sources and implications of physics identity differences across gender so that education researchers, physics departments, policy makers, and instructors can develop and implement more inclusive teaching approaches to address these gender discrepancies in physics classrooms.

\section{A. Implications for physics instruction}

We found that for female students, their peers' and TA or instructors' perceptions, which is part of their external identity, relate to their sense of belonging and self-efficacy. Positive or negative classroom experiences and classroom interactions with peers and course instructors can enhance or reduce female students' motivation to engage, as well as their course performance, persistence in the major and their identity as STEM major [37]. Our findings underline the important connection between students' self-efficacy and being identified by others as a physics person. Because of the negative societal stereotypes and biases, female students' self-efficacy may decrease and further negatively impact their identity in physics if the classroom environment is not equitable and inclusive.

We found that students' interest in physics was strongly connected to perception of oneself as a physics person, for both female and male students. This result highlights the importance of engaging students' interest into instructional strategies. For example, using relevant examples and class activities that tap into students' curiosity as well as tailoring physics curriculum into all students' learning goals can be a stepping stone to enhancing how female and male students identify themselves with physics. Students are more likely to develop positive physics identities if the topics they learn resonate with them. In this sense, our results show that using students' interest as a resource can be one way to improve students' learning and supporting their physics identity.

One of the other highlights of our results is that receiving positive recognition by the course instructor and teaching assistant as someone who is good at physics is particularly important for women and relates to their sense of belonging and self-efficacy. While feelings of being recognized by others can boost female students' feelings of belonging and external identities in a physics classroom, lack of recognition from TAs and instructors can particularly be detrimental to women's sense of belonging and self-efficacy. As an example, women, as a gender minority in physics courses, might experience constant fear of confirming the stereotypes about their gender in first-year physics courses and are more likely to think that their instructors or peers doubt their skills in physics when they ask them how to solve a problem and the instructor or TA respond by saying that the problem is trivial, obvious, or easy [112]. The ambiguity of what is meant by the instructor or TA might activate the stereotype threat and female students are likely to interpret it as being told they are not smart enough to do those types of problems and excel in the discipline. Additionally, our results revealed that female students possess negative beliefs about their TA/instructors' recognition in physics courses. Although instructors might intend to treat all students equally, they might carry subtle biases about students' competence based upon their gender, race or ethnicity, and they can implicitly or explicitly manifest these biases when interacting with students. Professional development can play an important role in helping TAs and instructors maintain an equitable and inclusive learning environment.

Peer interaction and recognition is also an influential factor that can moderate women's classroom experiences. Especially in active engagement classrooms that incorporate collaborative group problem solving and require frequent peer 
interaction [16], it is important to implement classroom activities in such a way that all students can equally benefit and feel valued [113]. Our research presented here shows that female students' perceived recognition from friends was related to the self-efficacy or belonging factor (in a similar way to TA or instructor recognition although with a smaller factor loading), while there was no such connection for male students. This result highlights the role of peer interaction which may be more related to female students' self-efficacy beliefs and sense of belonging in physics classes. Prior research shows that evidence-based, active-engagement methods help all students do better compared to traditional lecture courses, but such methods may also increase the gender gap in performance (instead of decreasing the gap) [113]. Negative peer interactions in active-engagement courses can be partially be responsible for such gender gap increase, especially in these classes where women are a minority. Such effects would align with the results found here in that peers' recognition is more strongly tied to women's self-efficacy and sense of belonging.

One factor to consider in improving peer interaction in physics courses is assigning task roles in a way that students can have equal learning opportunities and feel valued by the group members. In general, female students are often assigned to do menial tasks in cooperative activities (e.g., notetaking or data recording) and play less active roles, while male students are more likely assigned to leading roles, such as explaining materials to others $[37,75,76]$. In such group activities, female students might feel that their opinions are not considered, or they may feel that their contribution to group work are discounted, which can undermine their selfefficacy, sense of belonging, their perception of peer's recognition and their internal identity as a physics person. These differential learning experiences between female and male students can accumulate over time and lead to lack of gender parity in students' physics identities and performance (since these can feed on each other).

Furthermore, Whitten et al. [114] noted the importance of creating a female-friendly department culture in physics, particularly with the goal of supporting women's sense of belonging and thereby retention in STEM. Some of these factors include monitoring the student culture, implementing and supporting collaborative work, emphasizing female and ethnic or racial minorities' historical accomplishment in physics, or highlighting practical outcomes of physics to daily life [114]. Female students are more likely to value helping others and benefits to society whereas men are more likely to value financial goals, having power, or becoming famous [115]. Designing the physics courses in an equitable manner that serves diverse groups of students' values can increase their interest, achievement, and persistence in the domain and has the potential to further strengthen students' identity [95]. For instance, an intervention that highlights the value of biology to the students' goals closed the large performance gaps across different race groups in the introductory biology courses [116]. Moreover, Whitten et al. argue that making physics departments more family friendly can increase women's motivation to pursue physics as a career [114], considering that research shows the important role of work-family balance on women's career decisions [50]. Making these systematic improvements in the culture of a physics department can alter and enhance the learning environment for all students. Moreover, research also shows that these efforts to warm up a department's chilly environment benefit all students, but particularly those from minority groups [117].

Regarding the observed relations between perceived recognition and self-efficacy or belonging, there are relevant research-based classroom interventions that can be used to enhance students' sense of belonging and self-efficacy in physics [118-120]. For example, belonging-mindset interventions target removing feelings of uncertainty created when students ask themselves, Do people like me belong here? [117119]. These types of interventions acknowledge students' struggle in learning a new subject as normal and inform them that most students have similar difficulties. For this reason, it is important that instructors tailor these short interventions in their classes to create an inclusive learning environment and dispel students' stereotypical beliefs early on in the semester. Since our results suggest that physics instructors or TAs play an important role in female students' sense of belonging and selfefficacy, instructors can use classroom interventions in order to help them see that they are not the only ones struggling in learning physics. Implementing these classroom interventions may take some class time but they can have lasting effects in supporting women's STEM identities and creating more diverse and equitable learning spaces [118]. At our institution, we have conducted belonging-mindset intervention in the introductory level physics courses and our initial results show a reduced gender gap in Physics 1 grades for the intervention group while there still exist grade differences in the control group [117]. These preliminary results highlight the need for more inclusive physics learning environments to help all students learn physics equitably.

\section{B. Implications for STEM diversity}

Students with strong physics identities can have better achievement, engagement, and persistence in physics courses, which are foundational to their STEM majors $[33,101]$. Positive experiences in the first-year college courses, such as physics, can foster students' interest and retention in STEM majors. Research suggests that the most common dropout points for women from physical science or engineering pathways are during the first and second years [121]. Hewitt and Seymour extensively discussed the underlying reasons for first-year college students' decision to leave STEM fields, a majority of whom were women and underrepresented racial and ethnic minorities [78]. They found that the noninclusive STEM environments, negative classroom experiences (e.g., peers' biased attitudes), and lack of support and encouragement from instructors are 
some of the primary reasons for switching out of STEM [78]. Because of these types of factors, women can lose interest in pursuing STEM majors [100].

Likewise, these experiences in unwelcoming pillar STEM courses such as physics can adversely impact female students' identities in physics and also in other related STEM domains. When female students do not develop positive identities in physics courses, they may prefer not to pursue engineering degrees that use advanced levels of physics. The currently masculine culture of physics (as experienced through classroom interactions with peers and instructor or TA) involves a "chilly environment" which can lead women to reject physics as a plausible identity.

When we interviewed some first-year female engineering students during survey validation, these students tended to bring up their Physics 1 experiences. Some female students stated that they considered dropping Physics 1 during the semester because they did not like the experience in the classroom. Note that completion of Physics 1 and Physics 2 is required for all engineering majors. Another female student stated that she switched from mechanical engineering to industrial engineering (which involves a less physics-intensive curriculum) at the end of first semester because of her experiences in Physics 1.

Furthermore, lack of a sense of belonging in physics or not identifying oneself with physics can be detrimental in the long-term even for students who choose to continue in STEM fields. Female students, who often experience a lack of sense of belonging from the early years in many STEM disciplines, may continue to feel less capable than their male counterparts as they advance to STEM careers. If women undervalue their skills and develop less strong identities in STEM due to biases or stereotypes pervasive in these disciplines [92], they may fail to promote their strengths especially in the competitive and male-dominated STEM occupations. Vesturlund et al. found that female students are less likely to choose to compete against male students (as opposed to other women) despite their similar math skills and performance [122]. In our prior study, we similarly found that there were large self-efficacy gender gaps between similarly performing female and male students in physics courses [22,23].

Considering the possible consequences of identity gaps (e.g., physics or engineering identity) that develop early in STEM careers, the STEM culture in general must change in order to become more welcoming and less chilly for everyone at all levels; otherwise, the diversity issues in physics and other related STEM domains will perpetuate.

Even though we did not focus on the ethnic/racial students' identities in this study, we hypothesize that there might be further differences in some of interactions between the motivational constructs such as sense of belonging and identity if we carry out an intersectionality analysis in larger datasets to further uncover the layers of diversity issues in STEM [77,123].

\section{Limitations and future directions}

In this study, we focused on the quantitative aspects of male and female students' internal and external physics identities and how they relate to different motivational factors in a calculus-based introductory physics course. However, examining female students' experiences in STEM disciplines with a qualitative study can expand our current understanding of how motivational factors impact female students' identities, performance and decisions in STEM fields.

As illustrated earlier, in ambiguous situations, women are more likely to be victims of stereotype threat and negatively interpret what their physics TA or instructor think about them and whether they see them as a physics person. Our research presented here suggests that TA or/and instructor's views and communications can be extremely influential particularly for female students' sense of belonging, engagement and their physics identity. However, there might be some variations in students' responses to the survey questions if we had separated TA and instructor recognition as two separate questions. In particular, instructors teaching traditionally in large lecture halls have less opportunity to give students feedback, whereas TAs teach small recitation classes so that they can more frequently interact with each student and get to know them at personal level. Therefore, it would be worth conducting future investigation to investigate if the students' perception of TAs and instructors' recognition vary and play a different role in female students' sense of belonging and self-efficacy or whether they are similar. Also, since physics performance and self-efficacy can operate in a feedback loop, in the future, we aim to look at the interaction between learning outcome and selfefficacy at different time points, which can further impact students' physics identity.

Future work can further focus on investigating whether identity formation has a similar gendered patterned in physics courses that use different pedagogies (e.g., various evidencebased active-engagement classes) or at institutions that have different student demographics. One of the strengths and limitations of that current study is that it was conducted in a large research institution. It was a strength in that larger numbers of students were needed to conduct the factor analyses by gender. But it is a limitation in terms of generalizability: smaller or more teaching oriented universities may have different cultural contexts within the physics classrooms. Therefore, future studies need to test the replicability of the current findings in other kinds of institutions.

We also note that our gender data was limited to male vs female as a binary. However, gender is a multidimensional social construct and some students can have a nonbinary gender identity [7]. Therefore, for future data collection, we recommend collecting data on gender using a multiple option scale. Relatedly, examining possible interactions between gender and ethnicity or race can be very valuable to understand and further unpack equity issues in physics $[114,123]$. Collecting more data will allow us to further 
divide our data by ethnic or racial groups and investigate its relation across gender in students' physics identity.

Future research will also investigate male and female students' identity in algebra-based physics classes. Unlike calculus-based courses, women are often the majority group in algebra-based courses, often making up $60 \%$ or more of the classroom; the algebra-based physics courses are often selected by students interested in medicine and health-related professions, which are more common career goals among women. Since students' goals and aspirations are likely to be different in these courses compared to the calculus-based courses, there might be differences in students' motivational beliefs and attitudes and their relation to their physics identities. In addition, we intend to expand our research on this topic to physics courses intended for nonscience majors.
Finally, we note that future work should also focus not only on making learning environments more welcoming and inclusive for all students, but also investigate the implications for how socialization and culture impact the identity formation of female students in physics or physicsrelated majors.

\section{ACKNOWLEDGMENTS}

This work was supported by Grant No. DUE1524575 from the National Science Foundation and Grant No. 220020483 from the James S. McDonnell Foundation. Portions of these results were presented at the 2018 American Association of Physics Teachers Summer Meeting and Physics Education Research Conference.

\section{APPENDIX A: BY GENDER PCA SCREE PLOTS}

In Figure 3, we show the PCA Scree plots for female (top plot) and male (bottom plot) students. A scree plot indicates the eigenvalue from possible extracted factors in a principle component analysis, in order of eigenvalue. A cutoff value of 1 is often used as a threshold for inclusion of a factor. Another cutoff is at the point in which there is a clear inflection in the slope of the curve. Both of the figures suggest that three factors are a good choice.
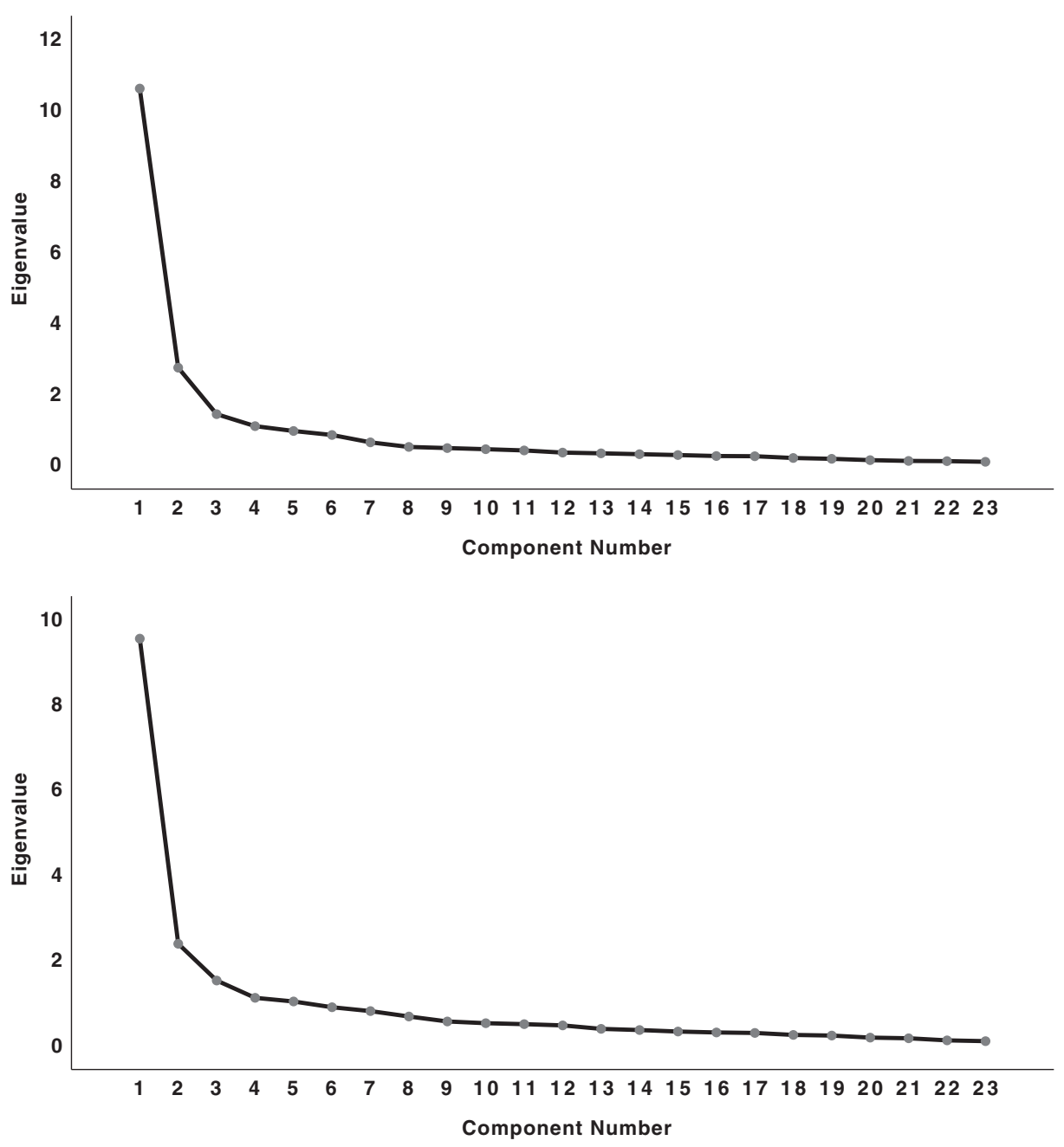

FIG. 3. The scree plots for the PCA analyses for female students (top) and male students (bottom). 


\section{APPENDIX B: THE COMPLETE SET OF PHYSICS MOTIVATIONAL SURVEY QUESTIONS}

The full set of 23 motivational survey items assessing attitudes towards physics included in the current analyses, along with the response options for each item.

1. I wonder about how physics works
A. Never
B. Once a month
C. Once a week
D. Every day

2. In general, I find physics
A. Very boring
B. boring
C. interesting
D. Very interesting

3. I want to know everything I can about physics

4. I am curious about recent discoveries in physics.

5. I want to know about the current research that physicists are doing.

6. I am able to help my classmates with physics in the laboratory or in recitation.

7. I understand concepts I have studied in physics.

8. If I wanted to, I could be good at physics research.

9. If I study, I will do well on a physics test.

10. If I encounter a setback in a physics exam, I can overcome it.

11. Learning physics will help me in courses in my major.

12. Learning physics will help me achieve admission into graduate school and/or medical school (select $\mathrm{E}$ if not applicable).

13. Learning physics will help me get a job that I want.

14. Learning physics will help me succeed in my future career.

15. I see myself as a physics person.

16. My family sees me as a physics person.

17. My friends see me as a physics person.

18. My physics instructor and/or TA sees me as a physics person.

19. I feel like an outsider in this class.

20. I feel comfortable in this class.

21. I feel like I can be myself in this class.

22. Sometimes I worry that I do not belong in this physics class.

23. When I get a poor grade on a physics assignment or exam, I feel that maybe I don't belong in a physics class.

\begin{tabular}{|c|c|c|c|c|}
\hline NO! & no & yes & & YES! \\
\hline A & B & $\mathrm{C}$ & & D \\
\hline A & B & $\mathrm{C}$ & & D \\
\hline A & B & $\mathrm{C}$ & & D \\
\hline A & B & $\mathrm{C}$ & & D \\
\hline A & B & $\mathrm{C}$ & & D \\
\hline A & B & $\mathrm{C}$ & & D \\
\hline A & B & $\mathrm{C}$ & & D \\
\hline A & B & $\mathrm{C}$ & & D \\
\hline Strongly & Disagree & Agree & & Strongly \\
\hline Disagree & & & & Agree \\
\hline A & B & $\mathrm{C}$ & & $\mathrm{D}$ \\
\hline A & B & $\mathrm{C}$ & & D \\
\hline A & B & $\mathrm{C}$ & & D \\
\hline A & B & $\mathrm{C}$ & & D \\
\hline A & B & $\mathrm{C}$ & & D \\
\hline A & B & $\mathrm{C}$ & & D \\
\hline A & B & $\mathrm{C}$ & & $\mathrm{D}$ \\
\hline A & B & $\mathrm{C}$ & & D \\
\hline $\begin{array}{l}\text { Not at } \\
\text { all true }\end{array}$ & $\begin{array}{l}\text { A little } \\
\text { true }\end{array}$ & $\begin{array}{l}\text { Somewhat } \\
\text { true }\end{array}$ & $\begin{array}{l}\text { Mostly } \\
\text { true }\end{array}$ & $\begin{array}{c}\text { Completely } \\
\text { true }\end{array}$ \\
\hline A & B & $\mathrm{C}$ & $\mathrm{D}$ & E \\
\hline A & B & $\mathrm{C}$ & D & E \\
\hline A & B & $\mathrm{C}$ & D & E \\
\hline A & B & $\mathrm{C}$ & D & E \\
\hline A & B & $\mathrm{C}$ & D & E \\
\hline
\end{tabular}

[1] National Student Clearinghouse Research Center, Science and Engineering Degree Attainment: 2004-2014 (2015); retrieved from https://nscresearchcenter.org/ snapshotreport-degreeattainment $15 /$.

[2] National Science Board Science and Engineering Indicators. National Science Foundation Report; retrieved from https://www. nsf.gov/statistics/2018/nsb20181/ digest/sections/preface.

[3] https://www.aip.org/statistics/data-graphics/percentphysics-bachelors-and-phds-earned-women-classes1975-through-2016.
[4] Women, Minorities, and Persons with Disabilities in Science, and Engineering, Occupation (2017); retrieved from https://nsf.gov/statistics/2017/nsf17310/ digest/occupation/women.cfm.

[5] L. Tsui, Effective strategies to increase diversity in STEM fields: A review of the research literature, J. Negro Educ. 76, 555 (2007).

[6] S. Eddy and S. Brownell, Beneath the numbers: A review of gender disparities in undergraduate education across science, technology, engineering, and math disciplines, Phys. Rev. Phys. Educ. Res. 12, 020106 (2016). 
[7] A. Traxler, X. Cid, J. Blue, and R. Barthelemy, Enriching gender in physics education research: A binary past and a complex future, Phys. Rev. Phys. Educ. Res. 12, 020114 (2016).

[8] A. Traxler and E. Brewe, Equity investigation of attitudinal shifts in introductory physics, Phys. Rev. ST Phys. Educ. Res. 11, 020132 (2015).

[9] R. Ivie, S. White, and R. Chu, Women's and men's career choices in astronomy and astrophysics, Phys. Rev. Phys. Educ. Res. 12, 020109 (2016).

[10] R. Ivie and K. Stowe, Women in Physics, 2000. AIP Report https://eric.ed.gov/?id=ED446559.

[11] P. V. Engelhardt, An introduction to classical test theory as applied to conceptual multiple-choice tests, in Getting started in PER, Reviews in PER, edited by C. Henderson and K. A. Harper (American Association of Physics Teachers, College Park, MD, 2009) Vol. 2.

[12] R. Henderson, G. Stewart, J. Stewart, L. Michaluk, and A. Traxler, Exploring the gender gap in the conceptual survey of electricity and magnetism, Phys. Rev. Phys. Educ. Res. 13, 020114 (2017).

[13] A. Madsen, S. McKagen, and E. Sayre, Gender gap on concept inventories in physics: What is consistent, what is inconsistent, and what factors influence the gap?, Phys. Rev. ST Phys. Educ. Res. 9, 020121 (2013).

[14] E. Brewe, V. Sawtelle, L. Kramer, G. O'Brien, I. Rodriguez, and P. Pamela, Toward equity through participation in Modeling Instruction in introductory university physics, Phys. Rev. ST Phys. Educ. Res. 6, 010106 (2010).

[15] J. Day, J. Stang, N. Holmes, D. Kumar, and D. Bonn, Gender gaps and gendered action in a first-year physics laboratory, Phys. Rev. Phys. Educ. Res. 12, 020104 (2016).

[16] M. Lorenzo, C. Crouch, and E. Mazur, Reducing the gender gap in the physics classroom, Am. J. Phys. 74, 118 (2006).

[17] B. A. Adegoke, Impact of interactive engagement on reducing the gender gap in quantum physics learning outcomes among senior secondary school students, Phys. Educ. 47, 462 (2012).

[18] E. Marshman, Z. Y. Kalender, C. Schunn, T. Nokes-Malach, and C. Singh, A longitudinal analysis of students' motivational characteristics in introductory physics courses: Gender differences, Canadian J. Phys. 96, 391 (2017).

[19] Z. Y. Kalender, E. Marshman, T. Nokes-Malach, C. Schunn, and C. Singh, Motivational characteristics of underrepresented ethnic and racial minority students in introductory physics courses, in Proceedings of the 2017 Physics Education Research Conference, Cincinnati, $\mathrm{OH}$, edited by L. Ding, A. Traxler, and Y. Cao (2018), pp. 204-207, https://doi.org/10.1119/perc.2017.pr.046.

[20] T. Nokes-Malach, E. Marshman, Z. Y. Kalender, C. Schunn, and C. Singh, Investigation of male and female students' motivational characteristics throughout an introductory physics course sequence, in Proceedings of the 2017 Physics Education Research Conference, Cincinnati, $\mathrm{OH}$, edited by L. Ding, A. Traxler, and Y. Cao (2018), pp. 276-279, https://doi.org/10.1119/perc .2017.pr.064.
[21] T. J. Nokes-Malach, Z. Y. Kalender, E. Marshman, C. D. Schunn, and C. Singh, Prior preparation and motivational characteristics mediate relations between gender and learning outcomes in introductory physics, in Proceedings of the 2018 Physics Education Research Conference, Washington, DC, edited by A. Traxler, Y. Cao, and S. Wolf (2019), https://doi.org/10.1119/perc.2018.pr.NokesMalach.

[22] Z. Y. Kalender, E. Marshman, T. Nokes-Malach, C. Schunn, and C. Singh, Large gender differences in physics self-efficacy at equal performance levels: A warning sign?, in Proceedings of the 2018 Physics Education Research Conference, Washington, DC, edited by A. Traxler, Y. Cao, and S. Wolf (2019), https://doi.org/ 10.1119/perc.2018.pr.Kalender.

[23] E. Marshman, Z. Y. Kalender, T. Nokes-Malach, C. Schunn, and C. Singh, Female students with A's have similar self-efficacy as male students with C's in introductory courses: A cause for alarm?, Phys. Rev. Phys. Educ. Res. 14, 020123 (2018).

[24] D. Hammer, Epistemological beliefs in introductory physics, Cognit. Instr. 12, 151 (1994).

[25] E. Redish, J. Saul, and R. Steinberg, Student expectations in introductory physics,, Am. J. Phys. 66, 212 (1998).

[26] K. Edmondson and J. Novak, The interplay of scientific epistemological views, learning strategies, and attitudes of college students, J. Res. Sci. Teach. 30, 547 (1993).

[27] S. Bates, R. Galloway, C. Lopston, and K. Slaughter, How attitudes and beliefs about physics change from high school to faculty, Phys. Rev. ST Phys. Educ. Res. 7, 020114 (2011).

[28] L. McDermott, Oersted medal lecture 2001: Physics education research-The key to student learning, Am. J. Phys. 69, 1127 (2001).

[29] G. Kortemeyer, Correlations between student discussion behavior, attitudes, and learning, Phys. Rev. ST Phys. Educ. Res. 3, 010101 (2007).

[30] J. M. Nissen and J. Shemwell, Gender, experience, and self-efficacy in introductory physics, Phys. Rev. Phys. Educ. Res. 12, 020105 (2016).

[31] H. Fencl and K. Scheel, Engaging students-An examination of the effects of teaching strategies on self-efficacy and course climate in a non-majors physics course, J. Coll. Sci. Teach. 35, 20 (2005).

[32] C. Lindstrøm and M. Sharma, Self-efficacy of first year university physics students: Do gender and prior formal instruction in physics matter?, Int. J. Innovation Sci. Math. Educ. 19, 1 (2011).

[33] Z. Hazari, G. Potvin, R. Lock, F. Lung, G. Sonnert, and P. Sadler, Factors that affect the physical science career interest of female students: Testing five common hypotheses, Phys. Rev. ST Phys. Educ. Res. 9, 020115 (2013); Z. Hazari, G. Sonnert, P. Sadler, and M. Shanahan, Connecting high school physics experiences, outcome expectations, physics identity, and physics career choice: A gender study, J. Res. Sci. Teach. 47, 978 (2010); Z. Hazari, R. Tai, and P. Sadler, Gender differences in introductory university physics performance: The influence of high school physics preparation and affective factors, Sci. Educ. 91, 847 (2007). 
[34] V. Sawtelle, E. Brewe, and L. Kramer, Exploring the relationship between self-efficacy and retention in introductory physics, J. Res. Sci. Teach. 49, 1096 (2012).

[35] A. Cavallo, W. Potter, and M. Rozman, Gender differences in learning constructs, shifts in learning constructs, and their relationship to course achievement in a structured inquiry, yearlong college physics course for life science majors, School Sci. Math. 104, 288 (2004).

[36] M. Wang and J. Degol, Motivational pathways to STEM career choices: Using expectancy-value perspective to understand individual and gender differences in STEM fields, Development policy review : the Journal of the Overseas Development Institute 33, 304 (2013).

[37] R. Felder, G. Felder, M. Mauney, C. Hamrin, and E. Dietz, A longitudinal study of engineering student performance and retention. III. Gender differences in student performance and attitudes, J. Engin. Educ. 84, 151 (1995).

[38] E. Lichtenberger and C. George-Jackson, Predicting high school students' interest in majoring in a STEM field: Insight into high school students' postsecondary plans, J. Career Techn. Educ. 28, 19 (2013).

[39] A. Wigfield et al. Motivation to succeed, in Handbook of Child Psychology Vol. 3 Social Emotional and Personality Development, edited by W. Damon and N. Eisenberg (Wiley New York, 2006).

[40] J. Eccles, Understanding women's educational and occupational choices, Psychol. Women Q. 18, 585 (1994).

[41] J. Smith, C. Sansone, and P. White, The stereotyped task engagement process: The role of interest and achievement motivation. J. Educ. Psychol. 99, 99 (2007).

[42] E. Seymour, Tracking the processes of change in US undergraduate education in science, mathematics, engineering, and technology, Sci. Educ. 86, 79 (2002).

[43] A. Diekman, E. Clark, A. Johnston, E. Brown, and M. Steinberg, Malleability in communal goals and beliefs influences attraction to STEM careers: Evidence for a goal congruity perspective, J. Pers. Soc. Psychol. 101, 902 (2011).

[44] S. Brainard and L. Carlin, A six-year longitudinal study of undergraduate women in engineering and science, J. Eng. Educ. 87, 369 (1998).

[45] S. Correll, Gender and the career choice process: The role of biased self-assessments, Am. J. Soc. 106, 1691 (2001).

[46] S. Correll, Constraints into preferences: Gender, status, and emerging career aspirations, Am. Soc. Rev. 69, 93 (2004).

[47] A. Strenta, R. Elliot, R. Adair, M. Matier, and J. Scott, Choosing and leaving science in highly selective institutions, Res. High. Educ. 35, 513 (1994).

[48] E. Pascarella and P. Terenzini, How College Affects Students: Findings and Insights From Twenty Years of Research (Jossey-Bass, San Francisco, CA, 1991).

[49] S. Cheryan and V. Plaut, Explaining underrepresentation: A theory of precluded interest, Sex Roles 63, 475 (2010).

[50] C. Hill, C. Corbett, and A. Rose, Why so few? Women in science, technology, engineering, and mathematics (2010). Retrieved from https://www.aauw.org/files/2013/02/ Why-So-Few-Women-in-Science-Technology-Engineeringand-Mathematics.pdf. http://onlinelibrary.wiley.com/doi/ 10.1002/j.2168-9830.2010.tb01066.x/epdf.
[51] S. Ahlqvist, B. London, and L. Rosenthal, Unstable identity compatibility: How gender rejection sensitivity undermines the success of women in science, technology, engineering and mathematics fields, Psychol. Sci. 24, 1644 (2013).

[52] R. M. Deci and E. L. Ryan, Intrinsic and extrinsic motivations: Classic definitions and new directions, Contemp. Educ. Psychol. 25, 54 (2000).

[53] P. R. Pintrich and D. Schunk, Motivation in Education: Theory, Research and Applications (Prentice Hall, Englewood Cliffs, NJ, 1996).

[54] A. Elliot and J. M. Harackiewicz, Approach and avoidance achievement goals and intrinsic motivation, J. Personality Soc. Psychol. 80, 501 (1996).

[55] W. K. Adams, K. K. Perkins, N. S. Podolefsky, M. Dubson, N. D. Finkelstein, and C.E. Wieman, New instrument for measuring student beliefs about physics and learning physics: The Colorado Learning Attitudes about Science Survey, Phys. Rev. ST Phys. Educ. Res. 2, 010101 (2006).

[56] A. Duckworth, C. Peterson, M. Matthews, and D. Kelly, Grit: Perseverance and passion for long-term goals, Personality Processes Indiv. Diff. 92, 1087 (2007).

[57] A. Duckworth and P. Quinn, Development and validation of the short grit scale (Grit-S), J. Personality Assess. 91, 166 (2009).

[58] C. Dweck, Mindset: The New Psychology of Success (Ballentine, New York, 2006); C. DweckSelf-theories: Their Role in Motivation, Personality, and Development (Psychology Press, Philadelphia, 1999).

[59] Z. Y. Kalender, E. Marshman, C. Schunn, T. J. NokesMalach, and C. Singh, Why female STEM majors don't identify with physics: They don't think others see them that way (to be published).

[60] P. Pintrich, A motivational science perspective on the role of student motivation in learning and teaching contexts, J. Educ. Psychol. 95, 667 (2003).

[61] J. L. Meece, A. Wigfield, and J. S. Eccles, Predictors of math anxiety and its influence on young adolescents' course enrollment intentions and performance in mathematics, J. Educ. Psychol. 82, 60 (1990).

[62] B. Zimmerman, Self-efficacy: An essential motive to learn, Contemp. Educ. Psychol. 25, 82 (2000).

[63] A. Wigfield and J. S. Eccles, Expectancy-value theory of achievement motivation, Contemp. Educ. Psychol. 25, 68 (2000).

[64] S. Hurtado, N. L. Cabrera, M. H. Lin, L. Arellano, and L. L. Espinosa, Diversifying science: Underrepresented student experiences in structured research programs, Res. High Educ. 50, 189 (2009).

[65] J. Stets, P. S. Brenner, P. J. Burke, and R. T. Serpe, The science identity and entering a science occupation, Social Science Research 64, 1 (2017).

[66] R. M. Rock, Z. Hazari, and G. Potvin, Physics Career Intentions: The Effect of physics identity, math identity, and gender, AIP Conf. Proc. 1513, 262 (2013).

[67] G. Potvin and Z. Hazari, The development and measurement of identity across the physical sciences, in Proceedings of the 2013 Physics Education Research Conference, Portland, OR, edited by P. V. Engelhardt, A. D. Churukian, and D. L. Jones (AIP, New York, 2013), pp. 281-284. 
[68] A. Godwin, G. Potvin, Z. Hazari, and R. Lock, Identity, critical Agency, and engineering: An affective model for predicting engineering as a career choice, J. Engin. Educ. 105, 312 (2016).

[69] H. B. Carlone and A. Johnson, Understanding the science experience of successful women of color: Science identity as an analytical lens, J. Res. Sci. Teach. 44, 1187 (2007).

[70] E. D. Tate and M. C. Linn, How does identity shape the experiences of women of color engineering students?, J. Sci. Educ. Technol. 14, 483 (2005).

[71] J. P. Gee, Identity as an analytical lens for research in education, Rev. Res. Educ. 25, 99 (2000).

[72] R. Ceglie, Underrepresentation of women of color in the science pipeline: The construction of science identities, J. Women Minorities Sci. Engin. 17, 271 (2011).

[73] American Institute of Physics, retrieved from https:// www.aip.org/sites/default/files/statistics/highschool/hsstudfemale-09.pdf-page $=4$.

[74] L. Archer, J. Moote, B. Francis, J. DeWitt, and L. Yeomans, The "Exceptional" physics girl: A sociological analysis of multimethod data from young women aged 10-16 to explore gendered patterns of post-16 participation, Am. Educ. Res. J. 54, 88 (2017).

[75] A. T. Danielsson, Exploring woman university physics students 'doing gender' and 'doing physics', Gender Educ. 24, 25 (2012).

[76] A. Gonzalves, Exploring how gender figures the identity trajectories of two doctoral students in observational astrophysics, Phys. Rev. Phys. Educ. Res. 14, 010146 (2018).

[77] N. M. Hewitt and E. Seymour, A long, discouraging climb, ASEE Prism 1, 24 (1992).

[78] E. Seymour and N. M. Hewitt, Talking About Leaving: Why Undergraduates Leave the Sciences (Westview Press, Boulder, CO, 1997).

[79] C. A. Moss-Racusin, J. F. Dovidio, V. L. Brescoll, M. J. Graham, and J. Handelsman, Science faculty's subtle gender biases favor male students, Proc. Natl. Acad. Sci. U.S.A. 109, 16474 (2012).

[80] S. Upson and L. F. Friedman, Where are the female geniuses?, Scientific American Mind 23, 63 (2012).

[81] L. Bian, S. J. Leslie, and A. Chimpian, Gender stereotypes about intellectual ability emerge early and influence children's interest, Science 355, 389 (2017).

[82] S. J. Leslie, A. Chimpian, M. Meyer, and E. Freeland, Women are underrepresented in disciplines that emphasize brilliance as the key to success, Science 347, 262 (2015).

[83] S. Delamont Women's Place in Education (Avebury Publishers, Brookfield, MA, 1996).

[84] E. A. Canning, K. Muenks, D. J. Green, and M. C. Murphy, STEM faculty who believe ability is fixed have larger racial achievement gaps and inspire less student motivation in their classes, Sci. Adv. 5, eaau4734 (2019).

[85] J. E. Stets and P. J. Burke, A sociological approach to self and identity, Handbook of Self and Identity (The Guilford Press, New York, 2003), p. 128.

[86] D. Oyserman, K. Elmore, and G. Smith, in Handbook of Self and Identity, edited by M. R. Leary and J. P. Tangney (Guilford Press, New York, 2011).
[87] K. L. Tonso, Student engineers and engineer identity: Campus engineer identities as figured world, Cultural Studies Sci. Educ. 1, 273 (2006).

[88] A. Bandura, Self-Efficacy: The Exercise of Control (W. H. Freedman, New York, 1997).

[89] A. M. Flowers III and R. Banda, Cultivating science identity through sources of self-efficacy, J. Multicultural Educ. 10, 405 (2016).

[90] C. Steele and J. Aronson, Stereotype threat and the intellectual test performance of African Americans, Attitudes Social Cogn. 69, 797 (1995).

[91] A. Maries, N. I. Karim, and C. Singh, Is agreeing with a gender stereotype correlated with the performance of female students in introductory physics?, Phys. Rev. Phys. Educ. Res. 14, 020119 (2018).

[92] J. L. Cundiff, T. K. Vescio, E. Loken, and L. Lo, Do gender-science stereotypes predict science identification and science aspirations among undergraduate science majors?, Social Psychol. Educ. 16, 541 (2013).

[93] G. C. Marchand and G. Taasoobshirazi, Stereotype threat and women's performance in physics, Int. J. Sci. Educ. 35, 3050 (2013).

[94] P. Vincent-Ruz and C. Schunn, The nature of science identity and its role as the driver of student choices, Int. J. STEM Educ. 5, 48 (2018).

[95] J. M. Harackiewicz, E. K. Barron, M. J. Tauer, and A. J. Elliot, Predicting success in college: A longitudinal study of achievement goals and ability measures as predictors of interest and performance from freshman year through graduation, J. Educ. Psychol. 94, 562 (2002).

[96] S. Hidi, Interest: A unique motivational variable, Educ. Res. Rev. 1, 69 (2006).

[97] S. Hidi and K. A. Renninger, The four-phase model of interest development, J. Educ. Psychol. 41, 111 (2006).

[98] R. Masika and J. Jones, Building student belonging and engagement: Insights into higher education students' experiences of participating and learning together, Teaching Higher Educ. 21, 138 (2016).

[99] C. Goodenow, Classroom belonging among early adolescent students: relationships to motivation and achievement, J. Early Adolesc. 13, 21 (1993).

[100] A. W. Astin, What Matters in College: Four Critical Years Revisited (Jossey-Bass, San Francisco, CA, 1993).

[101] K. M. Whitcomb, Z. Y. Kalender, C. Schunn, T. J. NokesMalach, and C. Singh, Laying a foundation for success in engineering coursework: A predictive model of the curricula (to be published).

[102] Activation Lab. Tools: measures and data collection instruments (2017). Available from: http://www .activationlab.org/tools/.

[103] W. K. Adams, K. K. Perkins, N. S. Podolefsky, M. Dubson, N. D. Finkelstein, and C. E. Wieman, New instrument for measuring student beliefs about physics and learning physics: The colorado learning attitudes about science survey, Phys. Rev. ST Phys. Educ. Res. 2, 010101 (2006); B. Zwickl, T. Hirokawa, N. Finkelstein, and H. Lewandowski, Epistemology and expectations survey about experimental physics: Development and initial results, Phys. Rev. ST Phys. Educ. Res. 10, 010120 (2014). 
[104] J. Schell and B. Lukoff, Peer instruction self-efficacy instrument. Developed at Harvard University. Unpublished Instrument coetta. 2010.

[105] S. Glynn, P. Brickman, N. Armstrong, and G. Taasoobshirazi, Science motivation questionnaire II: Validation with science majors and nonscience majors, J. Res. Sci. Teach. 48, 1159 (2011).

[106] PERTS Mindset survey retrieved 2019, https://survey .perts.net/share/dlmooc.

[107] R. Likert, A technique for the measurement of attitudes, Archives of Psychol. 140, 55 (1932).

[108] L. Cronbach, Coefficient alpha and the internal structure of tests, Psychometrika 16, 297 (1951).

[109] R. L. Gorsuch, Factor Analysis, 2nd ed. (L. Erlbaum Associates, Hillsdale, NJ, 1983).

[110] J. Cohen, Statistical Power Analysis for the Behavioral Sciences (L. Erlbaum Associates, Hillsdale, NJ, 1988).

[111] J. S. Eccles, A. Wigfield, and Schiefele, Motivation to Succeed, in Handbook of Child Psychology: Social, Emotional, and Personality Development, edited by W. Damon and N. Eisenberg (John Wiley \& Sons Inc., Hoboken, NJ, 1998).

[112] S. Cheryan, S. Ziegler, A. Montoya, and L. Jian, Why are some STEM fields more gender balanced than others?, Psychol. Bull. 143, 1 (2017).

[113] N. I. Karim, A. Maries, and C. Singh, Do evidencebased active-engagement courses reduce the gender gap in introductory physics, Eur. J. Phys. 39, 025701 (2018).

[114] B. L. Whitten, S. R. Foster, and M. L. Duncombe, What works for women in undergraduate physics?, Phys. Today 56, 46 (2003).

[115] A. E. Abele and D. Spurk, The dual impact of gender and the influence of timing of parenthood on men's and women's career development: Longitudinal findings, Int. J. Behav. Dev. 35, 225 (2011).

[116] J. M. Harackiewicz, E. A. Canning, Y. Tibbetts, S. J. Priniski, and J. S. Hyde, Closing achievement gaps with a utility-value intervention: Disentangling race and social class, J. Personal Social Psychol. 111, 745 (2016).

[117] K. R. Binning, N. Kaufmann, E. McGreevy, O. Fotuhi, S. Chen, E. Marshman, Z. Y. Kalender, L. Limeri, L. Betancur, and C. Singh, Changing social norms to foster the benefits of collaboration in diverse workgroups, unpublished manuscript, http://d-scholarship.pitt.edu/ 36006/.

[118] D. S. Yeager and G. M. Walton, Social-psychological interventions in education: They are magic, Rev. Educ. Res. 81, 267 (2011).

[119] G. M. Walton, C. Logel, J. M. Peach, S. J. Spencer, and M. P. Zanna, Two brief interventions to mitigate a "chilly climate" transform women's experience, relationship, and achievement in engineering, J. Educ. Psychol. 107, 468 (2015).

[120] A. Miyake, L. E. Kost-Smith, N. D. Finkelstein, S. J. Pollock, and G. L. Cohen, Reducing the gender achievement gap in college science: A classroom study of values affirmation, Science 330, 1234 (2010).

[121] I. Goodman, C. Cunningham, and C. Lachapelle, The Women's Experience in College Engineering. Retrieved from https://files.eric.ed.gov/fulltext/ED507395.pdf (2002).

[122] L. Vesterlund and M. Niederle, Do women shy away from competition? Do men compete too much?, Quart. J. Econ. 122, 1067 (2007).

[123] T. L. Strayhorn, College Students' Sense of Belonging: A Key to Educational Success for All Students (Routledge, New York, 2012). 